\title{
Biodigestão anaeróbia dos dejetos da bovinocultura de corte: influência do período, do genótipo e da dieta
}

\author{
Marco Antonio Previdelli Orrico Junior ${ }^{1}$, Ana Carolina Amorim Orrico ${ }^{2}$, Jorge de Lucas \\ Junior $^{3}$, Alexandre Amstalden Moraes Sampaio ${ }^{4}$, Alexandre Rodrigo Mendes Fernandes ${ }^{2}$, \\ Emanuel Almeida de Oliveira $^{5}$
}

\footnotetext{
${ }^{1}$ Doutorando do Programa de Pós-Graduação em Zootecnia - UNESP/Jaboticabal-SP. Bolsista do CNPq.

2 Faculdade de Ciências Agrárias - UFGD/Dourados-MS.

${ }^{3}$ Departamento de Engenharia Rural da Faculdade de Ciências Agrárias e Veterinária - UNESP/Jaboticabal-SP.

${ }^{4}$ Departamento de Zootecnia da Faculdade de Ciências Agrárias e Veterinária - UNESP/Jaboticabal-SP.

${ }^{5}$ Doutorando do Programa de Pós-Graduação em Zootecnia - UNESP/Jaboticabal-SP.
}

RESUMO - Objetivou-se com este estudo identificar possíveis alterações na composição e no processo de biodigestão anaeróbia dos dejetos produzidos por bovinos Canchim e Nelore em diferentes períodos do confinamento e alimentados com diferentes proporções de volumoso e concentrado. O experimento foi conduzido em delineamento inteiramente casualizado em esquema fatorial com parcela subdividida no tempo. As parcelas foram compostas por quatro tratamentos: dejetos provenientes de duas dietas ( $40 \%$ de volumoso e $60 \%$ de concentrado e $60 \%$ de volumoso e $40 \%$ de concentrado) e dois genótipos (Canchim e Nelore) e as subparcelas pelos três períodos de colheita dos resíduos (início, meio e final). A eficiência do processo de biodigestão foi avaliada pelas reduções de sólidos totais (ST), sólidos voláteis (SV), número mais provável (NMP) de coliformes totais e termotolerantes, demanda química e bioquímica de oxigênio, além da produção e dos potenciais de produção de biogás e metano. Não houve efeito do genótipo nem do período sobre a composição dos dejetos, no entanto o aumento da proporção de volumoso na dieta levou a menor eficiência do processo, pois foi observado aumento de 26,31\% no volume de metano produzido na dieta com $60 \%$ de concentrado com relação à dieta com $40 \%$, de concentrado. Também foram observadas importantes reduções no NMP de coliformes totais e termotolerantes ao final do processo, independentemente do tratamento testado.

Palavras-chave: biodigestor, Canchim, energia, metano, Nelore

\section{Anaerobic biodigestion of beef cattle manure: influence of period, genotype and diet}

\begin{abstract}
The objective of this study was to identify possible alterations in the composition and anaerobic biodigestion process of manure from Canchim and Nellore cattle in different periods in feedlot fed with different forage to concentrate ratios. The experiment was carried out in complete randomized design in factorial arrangement with time as sub-divided plot. Plots were established by four treatments: manure from two diets (40\% forage and $60 \%$ concentrate and $60 \%$ forage and $40 \%$ concentrate) and two genotypes (Canchim and Nellore) and sub-plots by three periods of manure collection (initial, intermediate and final). The efficiency of the composting process was evaluated by reductions of total solids, volatile solids, the most probable number (MPN) of total and thermotolerant coliforms, chemical and biochemical demand of oxygen, besides the production and potentials of biogas and methane production. There was no effect of genotype or period on manure composting; however, the increase in the forage proportion in the diet promoted the lower efficiency of the process, in which an increase of $26.31 \%$ was found for the volume of methane that was produced with diet with $60 \%$ concentrate in relation to the diet with $40 \%$ concentrate. Significant reductions in MPN of total and thermotolerant coliforms were also observed at the end of the process, regardless of the treatment tested.
\end{abstract}

Key Words: biodigestor, Canchim, energy, methane, Nellore

\section{Introdução}

De acordo com Al-Masri (2001), a extensão do impacto causado pelos dejetos pode ser reduzida com a utilização de sistemas de reciclagem energética e de nutrientes. A biodigestão anaeróbia é considerada um método eficiente no tratamento dos dejetos, pois estabiliza a matéria orgânica, reduz o número de microrganismos patogênicos, 
melhora as propriedades fertilizantes dos dejetos além de produzir o biogás, que é uma fonte alternativa de energia.

A biodigestão anaeróbia pode ser definida como uma complexa interação de microrganismos que degradam os diversos componentes orgânicos presentes no resíduo até a forma final de metano e dióxido de carbono, principalmente (Côté et al., 2006). Os nutrientes contidos nos dejetos garantem a sobrevivência e reprodução dos microrganismos presentes durante a biodigestão anaeróbia, permitindo que ocorra a degradação da fração orgânica não estável - portanto poluente, até a forma estável: o biofertilizante -, além de produzir o biogás (Alvarez \& Lidén, 2008).

Como todo processo biológico, a biodigestão anaeróbia depende de diversos fatores, entre eles podem ser citados a temperatura, o pH, o uso de inóculo, os teores de sólidos totais e a composição do material (Massé et al., 2008; Souza et al., 2005). Entre todos estes fatores, a composição do material influencia diretamente o potencial de degradação do substrato, por isso a extensão da produção de biogás a partir dos dejetos é dependente da alimentação dos animais. O potencial de produção de biogás a partir do dejeto de ruminantes pode variar de acordo com a qualidade nutricional dos alimentos fornecidos aos animais. Diferenças são esperadas entre dejetos coletados de animais mantidos em pastagens em relação aos de animais que recebem alguma suplementação alimentar, principalmente de alimentos concentrados (Orrico Junior et al., 2010). Em estudos realizados por Orrico et al. (2007) com os dejetos de caprinos leiteiros em confinamento, os melhores resultados para os parâmetros de redução de sólidos voláteis, produção total e potenciais de produção de biogás e metano foram obtidos quando os animais foram alimentados com dietas com maior proporção de concentrado.

Objetivou-se com este estudo identificar possíveis alterações na composição e no processo de biodigestão anaeróbia dos dejetos produzidos por bovinos Canchim e Nelore em diferentes períodos do confinamento e alimentados com diferentes proporções de volumoso e concentrado.

\section{Material e Métodos}

Este trabalho foi realizado no Laboratório de Biodigestão Anaeróbia do Departamento de Engenharia Rural com os animais e dejetos do setor de Bovinocultura da Faculdade de Ciências Agrária e Veterinárias UNESP Campus de Jaboticabal, São Paulo.

O experimento foi conduzido em delineamento inteiramente casualizado em esquema fatorial com parcela subdividida no tempo. As parcelas foram compostas por quatro tratamentos: dejetos provenientes de duas dietas ( $40 \%$ de volumoso e $60 \%$ de concentrado e $60 \%$ de volumoso e $40 \%$ de concentrado) e dois genótipos (Canchim e Nelore) e as subparcelas pelos três períodos de colheita dos resíduos (início, meio e final). Cada tratamento possuía cinco repetições (animais), totalizando 20 bovinos alojados em baias individuais.

As dietas foram formuladas para atender às exigências de animais com peso médio de $350 \mathrm{~kg}$ e idade em torno de 14 meses, prevendo-se ganhos de peso de 1,2 kg/dia (Tabela 1). Inicialmente, os animais foram adaptados às dietas por 21 dias para, então, se promover a coleta dos dejetos. Foram realizadas coletas a cada intervalo de 35 dias num total de três coletas (início, meio e fim do confinamento).

Os dejetos coletados foram utilizados para o abastecimento de biodigestores batelada de bancada com capacidade de 12 litros. Foram utilizados 20 biodigestores batelada de bancada ( 2 dietas $\times 2$ genótipos $\times 5$ repetições, biodigestores). A quantidade de inóculo foi fixa e representou $15 \%$ da massa seca utilizada no abastecimento dos biodigestores, sendo que o inóculo foi obtido a partir do efluente de biodigestores contínuos estabilizados (produção de biogás e teor de metano constante) e alimentados com dejetos de bovinos de mesma idade que os utilizados no trabalho. Este procedimento permitiu que os microrganismos presentes no inóculo se adaptassem mais facilmente ao substrato, acelerando assim as produções de biogás.

Os biodigestores utilizados são constituídos basicamente por três cilindros retos de PVC com diâmetros de 20, 25 e $30 \mathrm{~cm}$ acoplados sobre uma placa de PVC com $2,5 \mathrm{~cm}$ de espessura e podem ser caracterizados como biodigestores batelada de bancada, com capacidade média de 12 litros de substrato em fermentação. Os cilindros de 20 e $30 \mathrm{~cm}$ encontram-se inseridos um no interior do outro, de forma que o espaço existente entre a parede externa do cilindro

Tabela 1 - Composição (g/kg de matéria seca) das dietas experimentais

\begin{tabular}{lcccc}
\hline \multirow{2}{*}{ Ingrediente } & \multicolumn{2}{c}{ Relação volumoso:concentrado da dieta } \\
\cline { 2 - 5 } & \multicolumn{2}{c}{$40: 60$} & \multicolumn{2}{c}{$60: 40$} \\
& Nelore & Canchim & Nelore & Canchim \\
\hline Cana-de-açúcar & 600 & 600 & 400 & 400 \\
Grãos de girassol & 91 & 91 & 100 & 100 \\
Farelo de soja & 75 & 79 & 70 & 70 \\
Levedura & 44 & 40 & 138 & 138 \\
Milho grão & 175 & 175 & 280 & 280 \\
Ureia & 10 & 10 & 4 & 4 \\
Núcleo mineral & 3 & 3 & 5 & 5 \\
Bicarbonato & 2 & 2 & 3 & 3 \\
\hline
\end{tabular}

R. Bras. Zootec., v.41, n.6, p.1533-1538, 2012 
interior e a parede interna do cilindro exterior comporta um volume de água (selo de água), atingindo profundidade de $50 \mathrm{~cm}$. O cilindro de diâmetro intermediário tem uma das extremidades vedadas, conservando-se apenas uma abertura para descarga do biogás, e está emborcado no selo de água, para propiciar condições anaeróbias e armazenar o gás produzido.

Os volumes de biogás produzidos diariamente foram determinados medindo-se o deslocamento vertical dos gasômetros e multiplicando-se pela área da seção transversal interna dos gasômetros, ou seja, $0,0507 \mathrm{~m}^{2}$. Após cada leitura, os gasômetros foram zerados utilizando-se o registro de descarga do biogás. A correção do volume de biogás para as condições de 1 atm e $20^{\circ} \mathrm{C}$ foi efetuada com base no trabalho de Caetano (1985). O potencial de produção de biogás foi calculado dividindo-se a produção total de biogás e metano pela quantidade de sólidos totais e de sólidos voláteis adicionados e reduzidos durante o processo.

Os teores de metano $\left(\mathrm{CH}_{4}\right)$ foram quantificados semanalmente em cromatógrafo de fase gasosa Finigan GC-2001, equipado com as colunas Porapack Q e Peneira Molecular, e detector de condutividade térmica.

Os teores de sólidos totais (ST), sólidos voláteis (SV), nitrogênio (N) demanda química de oxigênio (DQO), demanda bioquímica de oxigênio (DBO) e número mais provável (NMP) de coliformes totais e termotolerantes avaliados nos afluente e efluente dos biodigestores batelada de bancada foram determinados segundo Apha (2005). Os teores de fibras em detergente neutro e ácido, celulose, hemicelulose e lignina presentes no afluente foram avaliados conforme Silva \& Queiroz (2006). O teor de carboidratos de rápida degradação (CHOr) foi calculado de acordo com equação proposta por Moller et al. (2004).

Os resultados foram submetidos à análise de variância, considerando como fontes de variação o tipo de dieta, o genótipo, o período de coleta e a interação dos mesmos.
As análises foram feitas utilizando-se o software SAEG versão 9.1, adotando-se $\alpha=0,01$.

\section{Resultados e Discussão}

Não foi observado efeito $(\mathrm{P}>0,01)$ do genótipo nem dos períodos de coleta do resíduo sobre o processo de biodigestão anaeróbia dos dejetos produzidos por bovinos. Esse comportamento parece condizente com o fato de não terem sido evidenciadas diferenças $(P>0,01)$ na composição química dos dejetos entre genótipos e entre períodos de colheita. Resultado diferente foi encontrado por Orrico et al. (2007), que observaram influência do período e do genótipo sobre a composição química dos dejetos de cabras. Um dos possíveis motivos para a ausência de diferenças $(\mathrm{P}>0,01)$ entre os genótipo é o fato de ambos apresentarem desempenho muito similar durante o confinamento, resultando em ganho de peso praticamente igual. Este comportamento pode ocorrer principalmente quando se utilizam animais com elevado potencial genético. No caso do trabalho de Orrico et al. (2007), citado anteriormente, os autores compararam animais de genótipos com diferentes aptidões (genótipo Saanen (raça leiteira) e genótipo $1 / 2$ Saanen $1 / 2$ Boer ( $1 / 2$ leite $1 / 2$ corte) ) e constataram diferenças $(\mathrm{P}<0,05)$ na composição dos resíduos.

Foram observadas diferenças $(\mathrm{P}<0,01)$ na composição dos dejetos quando houve mudança na proporção volumoso:concentrados das dietas (Tabela 2).

Os dejetos produzidos a partir da dieta com menor proporção de volumoso (40:60) apresentaram maiores teores de carboidratos de rápida degradação (CHOr) e menores teores das frações fibrosas, como consequência da maior proporção de concentrado na dieta. Foram observados aumentos de 9,$4 ; 10,36$ e 22,3\% nos teores de FDN, FDA e lignina, respectivamente, à medida que a dieta passou de $40 \%$ de volumoso para $60 \%$ de volumoso. Esses

Tabela 2 - Caracterização dos dejetos produzidos por bovinos nelores alimentados com dietas com diferentes relações volumoso:concentrado

\begin{tabular}{|c|c|c|c|c|}
\hline Item & \multicolumn{2}{|c|}{ Relação volumoso:concentrado } & Valor P & $\mathrm{CV}, \%$ \\
\hline Sólidos totais (g/kg de $\mathrm{MN}$ ) & 355,2 & 333,5 & 0,098 & 13,4 \\
\hline Sólidos voláteis (g/kg de $\mathrm{MN}$ ) & 324,5 & 304,9 & 0,089 & 13,4 \\
\hline Nitrogênio (g/kg de ST) & 22,5 & 20,0 & 0,005 & 18,9 \\
\hline CHOr (g/kg de ST) & 196,4 & 156,0 & 0,009 & 12,3 \\
\hline Lignina (g/kg de ST) & 67,5 & 82,7 & 0,003 & 10,9 \\
\hline Celulose (g/kg de ST) & 242,1 & $25,9,0$ & 0,008 & 12,3 \\
\hline Hemicelulose (g/kg de ST) & 292,6 & 317,3 & 0,007 & 13,5 \\
\hline
\end{tabular}

MN - matéria natural; ST - sólidos totais; CHOr - carboidrato de rápida degradação; FDN - fibra em detergente neutro; FDA - fibra em detergente ácido. 
resultados estão próximos aos encontrados por Orrico Junior et al. (2010), que obtiveram aumentos de 5,0; 10,3; 25,6\% para os mesmos parâmetros e dietas.

As mudanças na composição dos dejetos influênciaram o processo de biodigestão anaeróbia, principalmente quanto às reduções de sólidos totais, sólidos voláteis, demanda química de oxigênio e demanda bioquímica de oxigênio (Tabela 3).

O benefício ocasionado pela adição de alimento concentrado à dieta dos animais sobre a degradação dos substratos pode estar relacionado aos menores teores de constituintes fibrosos (celulose, hemicelulose e lignina conforme dados apresentados na Tabela 2), que em menores quantidades podem ter favorecido as maiores reduções de sólidos totais, sólidos voláteis, demanda química de oxigênio e demanda bioquímica de oxigênio. Francou et al. (2008) chegaram à conclusão de que a lignina é a principal responsável por retardar a decomposição da matéria orgânica, sendo que a velocidade da biodegradação de um material orgânico depende do seu conteúdo de lignina. Resultado semelhante ao obtido no experimento foi encontrado por Orrico et al. (2007) em estudo sobre a interferência da relação volumoso e concentrado no processo de biodigestão anaeróbia dos dejetos de cabritas Saanen. Esses autores encontraram alta correlação entre o aumento da quantidade de concentrado na dieta e a eficiência de degradação do material nos biodigestores. As médias de redução de sólidos voláteis foram: 45\% para a dieta contendo $40 \%$ volumoso e $60 \%$ concentrado, $35 \%$ para a dieta contendo $60 \%$ volumoso e $40 \%$ concentrado e $27 \%$ para a dieta contendo $80 \%$ volumoso e $20 \%$ concentrado.

A maior degradação dos dejetos provenientes da dieta com maior proporção de concentrado refletiu diretamente sobre a produção e os potenciais de produção de biogás e metano, de modo que, com o aumento da qualidade dos dejetos (maior proporção de concentrado na dieta), maiores foram as produções e os potenciais de produção de biogás e metano (Tabela 4).

Com relação às dietas testadas, foi observado aumento de $26,31 \%$ no volume de metano produzido na dieta com $60 \%$ concentrado com relação à dieta de $40 \%$ de concentrado. Quando se fez a mesma comparação com base nos potenciais de produção de metano por kg de sólidos voláteis adicionado, o aumento encontrado foi de $25 \%$. Os potenciais de produção de metano encontrado neste trabalho são superiores aos descritos por Alvarez et al. (2006), que

Tabela 3 - Redução de sólidos totais, sólidos voláteis, demanda química de oxigênio e demanda bioquímica de oxigênio durante a biodigestão anaeróbia dos dejetos produzidos por bovinos alimentados com dietas com duas relações volumoso:concentrado

\begin{tabular}{|c|c|c|c|c|}
\hline \multirow[t]{2}{*}{ Redução (kg/kg) } & \multicolumn{2}{|c|}{ Relação volumoso:concentrado } & \multirow[t]{2}{*}{ Valor P } & \multirow[t]{2}{*}{$\mathrm{CV}, \%$} \\
\hline & $40: 60$ & $60: 40$ & & \\
\hline Sólidos totais & 0,378 & 0,303 & 0,009 & 15,98 \\
\hline Sólidos voláteis & 0,368 & 0,303 & 0,007 & 12,22 \\
\hline Demanda química de oxigênio & 0,258 & 0,208 & 0,005 & 15,45 \\
\hline Demanda bioquímica de oxigênio & 0,241 & 0,198 & 0,004 & 18,90 \\
\hline
\end{tabular}

Tabela 4 - Produção e potenciais produção de biogás e metano durante a biodigestão anaeróbia dos dejetos produzidos por bovinos alimentados com dietas com duas relações volumoso:concentrado

\begin{tabular}{lccc}
\hline Redução (kg/kg) & \multicolumn{2}{c}{ Dietas } & Valor P \\
\cline { 2 - 3 } & $40: 60$ & $60: 40$ & \\
\hline Biogás & & & 0,001 \\
Produção em litros (L) & 310 & 270 & 0,002 \\
L/kg/ de ST adicionado & 370 & 280 & 0,003 \\
L/kg/ de ST reduzido & 240 & 870 & 0,003 \\
L/kg/ de SV adicionado & 420 & 300 & 0,007 \\
L/kg/ de SV reduzido & 1550 & 920 & 13,45 \\
Metano & & & 0,006 \\
Produção em litros (L) & 240 & 190 & 0,008 \\
L/kg/ de ST adicionado & 250 & 200 & 0,005 \\
L/kg/ de ST reduzido & 670 & 500 & 0,004 \\
L/kg/ de SV adicionado & 300 & 240 & 0,002 \\
L/kg/de SV reduzido & 820 & 620 & 12,34 \\
\hline
\end{tabular}

ST - sólidos totais; SV - sólidos voláteis. 
observaram potencial de produção de metano de 131 litros $/ \mathrm{kg}$ de sólidos voláteis adicionado quando submeteram dejeto de bovino a um tempo de retenção hidráulica de 50 dias. O motivo desta diferença pode estar na dieta oferecida aos animais, a qual era baseada apenas em alimento volumoso. Moller et al. (2004) estudaram potenciais de produção de metano de bovinos submetidos a diferentes dietas e encontraram potencial de 100 litros/kg de sólidos voláteis adicionado para uma dieta $100 \%$ de volumoso ou seja muito próximo ao encontrado por Alvarez et al. (2006).

Ainda no estudo de Moller et al. (2004), também foi observado aumento nos potenciais de produção de metano conforme elevaram a proporção de concentrado na dieta dos bovinos. Os autores encontraram potenciais de produção de metano de 150 e 207 litros/kg de sólidos voláteis adicionados, para as dietas de 23 e $48 \%$ de concentrado, respectivamente.

Não foram observadas diferenças $(\mathrm{P}>0,01)$ entre as dietas no número mais provável de coliformes totais e termotolerantes (Tabela 5). As reduções de coliformes totais e termotolerantes foram elevadas, acima de 99,99\%, comprovando a eficiência do processo de biodigestão anaeróbia na remoção de microrganismos indicadores de poluição fecal.
Resultados semelhantes foram encontrados por Coté et al. (2006), que observaram eficiência de 97,94 a 100\% nas reduções de coliformes termotolerantes e totais durante a biodigestão anaeróbia dos dejetos de suínos, mesmo quando estes foram submetidos em condições de baixa temperatura $\left(20^{\circ} \mathrm{C}\right)$. Segundo os mesmos autores, a eficiência na redução dos microrganismos patogênicos está associada à temperatura de fermentação e ao tempo de retenção hidráulica utilizado, sendo que, quanto maiores os seus valores, mais eficiente será a redução de patógenos. Em estudo realizado por Mentz et al. (2004), a biodigestão anaeróbia foi eficiente para eliminar o parasita Fasciola hepatica presente no dejeto de bovino. Segundo os autores, para que possa ser utilizado com fertilizante sem acarretar problemas à saúde animal e humana, o período de retenção do material não deve ser inferior a 42 dias.

Os números de coliformes não ultrapassou os limites recomendados para o uso na irrigação de hortaliças, plantas frutíferas e de parques, jardins, campos de esporte e lazer, com os quais o público possa vir a ter contato direto (Conama, 2005). Esses resultados comprovam a segurança do uso dos biofertilizantes em áreas agrícolas de forma a agregar valor à produção sem prejuízos ao meio ambiente e a saúde da população.

Tabela 5 - Número mais provável (NMP) de coliformes totais e termotolerantes no afluente e efluente no processo de biodigestão anaeróbia dos dejetos produzidos por bovinos alimentados com dietas com duas relações volumoso:concentrado

\begin{tabular}{|c|c|c|c|c|}
\hline \multirow[t]{2}{*}{ NMP } & \multicolumn{2}{|c|}{ Relação volumoso:concentrado } & \multirow[t]{2}{*}{ Valor $\mathrm{P}$} & \multirow[t]{2}{*}{$\mathrm{CV}, \%$} \\
\hline & $40: 60$ & $60: 40$ & & \\
\hline Afluente & $1,50 \times 10^{8}$ & $5,00 \times 10^{7}$ & 0,345 & 12,34 \\
\hline Afluente & $5,87 \times 10^{7}$ & $9,00 \times 10^{6}$ & 0,237 & 13,40 \\
\hline Efluente & 2,60 & 7,00 & 0,067 & 18,54 \\
\hline
\end{tabular}

\section{Conclusões}

O aumento na proporção de concentrado na dieta de bovinos promove ampliação na eficiência e na produção de metano no processo de biodigestão anaeróbia dos dejetos de bovinos.

\section{Referências}

AL-MARSI, M.R. Changes in biogas production due to different ratios of some animal and agricultural wastes. Bioresource Technology, v.77, p.97-100, 2001.

ALVAREZ, R.; LIDÉN, G. Semi-continuous co-digestion of solid slaughterhouse waste, manure, and fruit and vegetable waste. Renewable Energy, v.33, n.2, p.726-734, 2008.
ALVAREZ, R.; VILLCA, S.; LIDÉN, G. Biogas production from llama and cow manure at high altitude. Biomass and Bioenergy, v.30, n.3, p.66-75, 2006.

AMERICAN PUBLIC HEALTH ASSOCIATION - APHA. Standard methods for examination of water and wastewater. 21.ed. Washington: American Water Works Association, 2005. 1368p.

CAETANO, L. Proposição de um sistema modificado para quantificação de biogás. 1985. 75f. Dissertação (Mestrado em Energia na Agricultura) - Faculdade de Ciências Agronômicas, Universidade Estadual Paulista, Botucatu.

CONSELHO NACIONAL DO MEIO AMBIENTE - CONAMA. Padrões de qualidade para os parâmetros monitorados na rede de monitormento. Resolução CONAMA 20/86. Disponível em: <http://www.cetesb.sp.gov.br/QualidadeRios/ anexo2>. Acesso em: 1 abr. 2005.

CÔTE, C.; MASSE, D.I.; QUESSY, S. Reduction of indicator and pathogenic microorganisms by psychrophilic anaerobic 
digestion in swine slurries. Bioresource Technology, v.97, n.1, p.686-691, 2006.

FRANCOU, C.; LINERES, M.; DERENE, S. et al. Influence of green waste, biowest and paper-cardboard initial rations on organic matter transformation during composting. Bioresource Technology, v.99, n.18, p.8926-8934, 2008.

MASSÉ, D.I.; MASSE, L.; HINCE, J.F. et al. Psychrophilic anaerobic digestion biotechnology for swine mortality disposal. Bioresource Technology, v.99, n.3, p.7307-7311, 2008.

MENTZ, M.B.; WIEST, J.M.; GONCALVES, P.C. Viabilidade de ovos de Fasciola hepatica de bovinos em sistema de biodigestão anaeróbia. Arquivos Brasileiros de Medicina Veterinária e Zootecnia, v.56, n.4, p.550-553, 2004.

MOLLER, H.B.; SOMMER, S.G.; AHRING, B.K. Methane productivity of manure, straw and solid fractions of manure. Biomass Bioenergy, v.26, n.3, p.485-495, 2004.
ORRICO JUNIOR, M.A.P.; ORRICO, A.C.A.; LUCAS JUNIOR, J. Influência da relação volumoso: concentrado e do tempo de retenção hidráulica sob a biodigestão anaeróbia de dejetos de bovinos. Engenharia Agrícola, v.30, n.3, p.386-394, 2010.

ORRICO, A.C.A.; LUCAS JÚNIOR, J.; ORRICO JÚNIOR, M.A.P. Caracterização e biodigestão anaeróbia dos dejetos de caprinos. Engenharia Agrícola, v.27, n.3, p.639-647, 2007.

SILVA, D.J.; QUEIROZ, A.C. Análise de alimentos: métodos químicos e biológicos. 3.ed. Viçosa, MG: Editora Universitária, 2006. 166p.

SOUZA, C.F.; LUCAS JUNIOR, J.; FERREIRA, W.P.M. Biodigestão anaeróbia de dejetos de suínos sob efeito de três temperaturas e dois níveis de agitação do substrato: considerações sobre a partida. Engenharia Agrícola, v.25, n.2, p.530-539, 2005. 